\title{
Article \\ Wheel Deflection Control of Agricultural Vehicles with Four-Wheel Independent Omnidirectional Steering
}

\author{
Qimeng Xu, Hongwen Li *, Quanyu Wang and Chunlei Wang
}

check for updates

Citation: Xu, Q.; Li, H.; Wang, Q.; Wang, C. Wheel Deflection Control of Agricultural Vehicles with Four-Wheel Independent Omnidirectional Steering. Actuators 2021, 10, 334. https://doi.org/ $10.3390 /$ act10120334

Academic Editor: Gianluca Palli

Received: 3 October 2021

Accepted: 10 December 2021

Published: 16 December 2021

Publisher's Note: MDPI stays neutral with regard to jurisdictional claims in published maps and institutional affiliations.

Copyright: (c) 2021 by the authors. Licensee MDPI, Basel, Switzerland. This article is an open access article distributed under the terms and conditions of the Creative Commons Attribution (CC BY) license (https:/ / creativecommons.org/licenses/by/ $4.0 /)$.
College of Engineering, China Agricultural University, Beijing 100083, China; xuqimeng@cau.edu.cn (Q.X.); quanyu0614@163.com (Q.W.); chlwang@cau.edu.cn (C.W.)

* Correspondence: lhwen@cau.edu.cn; Tel.: +86-10-62737631

Abstract: Due to the harsh working environment of wheeled agricultural vehicles in the field, it is difficult to ensure that all wheels make contact with the ground at the same time, which is easy to unequally distribute the yaw moments of each independent wheel. The commonly used vehicle lateral control methods are mostly controlled by coordinating the individual torque between different wheels. Obviously, this control method is not suitable for agricultural four-wheeled vehicles. The goal of this study was to provide a wheel steering angle control method that uses electric push rods as actuators that can cope with this problem. The design of a four-wheel steering controller generally adopts the linear PID control method, but the research object of this paper is difficult to establish an accurate and linear mathematical model due to the complex working environment. Therefore, fuzzy adjustment is added on the basis of PID control, which can meet the requirements of model difficulty and control accuracy at the same time. In order to verify the feasibility and rationality of the designed wheel steering mechanism, the model dynamics simulation based on ADAMS software and the response analysis of the electric linear actuator thrust were completed. Based on the kinematics model of the controlled object, the rotation angle of the actuator motor is used as the control target, the lateral deviation $e$ and deviation variation $e c$ are taken as input variables and the parameters $K_{P}, K_{I}$ and $K_{D}$ are taken as output variables, thereby establishing a fuzzy PID controller. Then, this controller is constructed in the Matlab/ Simulink simulation environment to analyze the lateral deviation and response stability during the process of vehicle path tracking. From the verification results of the linear path walking test under the fuzzy PID control method, the maximum lateral deviation of vehicle chassis is $2.7 \mathrm{~cm}$ when the driving speed is set as $1 \mathrm{~m} / \mathrm{s}$, and the deviation adjustment stable time of the system is $0.15 \mathrm{~s}$. It can be seen that the proposed steering control strategy has good response performance and effectively increases the steering stability.

Keywords: agricultural vehicle; omnidirectional steering; modeling; ADAMS; fuzzy PID control

\section{Introduction}

Aiming at better utilization of the cultivated area and developing agricultural automation, the application of advanced techniques, such as artificial intelligence and a new generation of information technology in Precision Agriculture (PA), make it is possible for unmanned production operation mode to be widely applied. Using the idea of robotics to develop autonomous mobile robots, agricultural vehicles and small unmanned aerial vehicles (UAV) for farming applications, can solve the problems affected by some factors in traditional agriculture, such as farming season, operator experience and driving fatigue, bringing the innovation of machines to replace human labor. An autonomous agricultural vehicle is mainly used as a mobile carrying platform for fruit bagging, picking, transportation, pesticide application and field information acquisition [1,2], which provides an effective solution for reducing the labor force and improving production efficiency. Compared to traditional large tractors and machinery, the development trend of mobile robots and autonomous vehicles for agricultural specific tasks is mainly to improve efficiency and 
provide better results, such as reducing soil compaction and machine operator absence [3]. Moreover, as one of the important factors affecting the driving performance of a wheeled autonomous agricultural vehicle, the design and control method of the steering system has become a hot and interesting topic over the past few decades.

Compared to the traditional front-wheel-steering (FWS) vehicles, the four-wheel independent steering electric vehicle with steer-by-wire (SBW) system has better handing stability and path-tracking [4]. The steering control system of a four-wheel vehicle is basically designed according to the Ackerman steering principle (ASP), applying this principle to the coordinated motion control strategy of agricultural robots can greatly reduce the tire sideslip in curve tracking [5]. Many works, such as [6-8], highlight the use of mobile vehicles with independent steering on all four wheels. Song designed a four-wheel chassis structure and electrical control system of an omnidirectional automated guided vehicle (AGV) robot through a digital structure, which has better omnidirectional movement performance. It can be verified that the design realizes flexible operation of zero turning radius and 360-degree omnidirectional movement in limited space [9]. Qu provided a coupling control method, which mainly aimed at the problem of the lack of linkage relationships between the four independent steering mechanisms when the flexible chassis (FC) adopts the traditional distributed control method. To shorten the response time and reduce steady-state errors of steering tracking motion, a fuzzy proportional integral (PI) controller was designed for steering tracking control. [10].

In addition to the four-wheel steering control method reviewed above, the direct yaw moment control (DYC) [11-13] method also has a significant control effect on the stability of the vehicle chassis under extreme road conditions. DYC system judges the steering intention by collecting the steering angle signal and then distributes the longitudinal force of the tire, thereby generating the yaw moment to regulate the yaw motion of the vehicle. Aiming at the limitations of the traditional DYC control method on parameter variation and robustness, Peng formulated a novel DYC method, which adopted a robust model predictive control (MPC) with a finite time horizon to realize the coordinated path tracking [14]. There is also an integrated algorithm for enhancing vehicle stability with the coordination of four-wheel steering and direct yaw moment control. Its operating principle is to derive the desired four-wheel steering angles and yaw moment by using sliding mode control technology so as to control the wheel steering movement [15]. As the basis of the DYC system, torque distribution control [16-18] can make up for the low environmental adaptability and low distribution accuracy of the DYC method, thereby improving the control performance of DYC. Yin proposed a new distribution control to allocate driving torques to four-wheel motors, which focuses on the global yaw moment generated by both longitudinal and lateral tire forces with a quicker yaw response [19]. In addition, the accuracy of the controller can also be optimized to improve the stability robustness of the steering control system [20,21]. Focusing on the vehicle stability and path following performance in unmanned ground vehicle (UGVs) diagonal steering, an integrated robust dynamics controller was extended by Zhang [22]. Similarly, a control strategy based on the MPC method can directly optimize the control input by simplifying the hierarchical structure of the controller [23]. Tu reported a robust controller based on backstepping sliding mode control (SMC) for a four-wheel steering (4WS) agricultural robotic vehicle. Furthermore, a kinematic model of the steering wheel, as well as its corresponding navigation controllers, was developed [24].

Nevertheless, these control methods are not completely applicable to the research object of this article. Due to the harsh working environment of wheeled agricultural vehicles in the field, the soil road conditions are changeable and uneven. Therefore, the four tires cannot be guaranteed to be in contact with the ground at the same time, which, in turn, causes the vehicle chassis to be in an unstable state due to uneven support forces. In this case, if the DYC method is used to study the individual torque of each wheel, it is not easy to equally distribute the yaw moments of the four independent wheels, but also the coordination of the vehicle in the four-wheel steering process cannot be guaranteed. 
To address these issues, this paper focused on a wheel steering angle control method that used an electric linear actuator as the executive unit, which is carried out by the design of a four-wheel independent steering mechanism and a steering controller.

The lateral stability control of agricultural vehicles mostly adopts the ProportionIntegration-Differentiation (PID) control regulator, which has the advantages of a simple structure, good control effect and strong robustness. However, it is difficult to adjust the control parameters, and there will be the contradiction problems between overshoot and response time [25]. The fuzzy control method does not need to establish an accurate mathematical model of the controlled object. Its core is to use the formulated fuzzy rules to control the system, which has good adaptability. However, the fuzzy control has the problem of low control accuracy, so it is often used through a fusion and combination algorithm [26]. This paper adopts the wheel deflection control method based on the Fuzzy PID algorithm by adding a fuzzy adjustment link on the basis of the PID control, the online adjustment of the PID control parameters is realized and the path tracking is optimized by controlling the change of the wheel steering angle of the agricultural vehicle.

The objective of this paper is to provide a wheel steering angle control method that uses electric push rods as actuators to realize four-wheel independent omnidirectional steering, which can reduce linear tracking error and guarantee the lateral stability of the vehicle. To achieve this, a four-wheel steering kinematic model is established based on the Ackerman principle. To satisfy the requirements of the modeling difficulty and control accuracy at the same time, a fuzzy PID controller is employed for steering tracking control. The feasibility of the control strategy was simulated by Matlab/ Simulink, and then we conducted a field experiment to verify the tracking error. Furthermore, the steering angle of the controlled wheel and the displacement of the piston rod present are confirmed to have a linear positive correlation.

\section{Vehicle Model and Steering Analysis}

This paper developed an electric power steering (EPS) control system, which used an electric linear actuator as the assisted steering executive unit. This system detects the actual wheel deflection angle through the angular encoder and then transmits the signal to the upper computer controller (UCC). The UCC would process the angular encoder data and generate a result. Then, the result is converted into a corresponding output signal, which would trigger the electric linear actuator to adjust the linear expansion of the push rod to change the displacement, thus realizing the target deflection. In this paper, a four-wheel drive (4WD) and 4WS agricultural vehicle [27] were used as an implementation carrier of the EPS control system. The vehicle uses a central controller to coordinate four servo motors and four steering actuators to complete chassis walking and omnidirectional steering. Four-wheel drive has good handling and tracking, which can provide strong power and stability, that is suitable for complex farmland operating environments.

\subsection{Steering System Hardware Structure Model}

The steering control system of the wheeled agricultural vehicle is composed of a singlechip microcomputer (SCM) controller (5 V, Guangzhou Xingyi Electronic Technology Co., Ltd. STM32F103ZET6, Guangzhou, China), L298 motor drive module (160 W/7 A, Dual Direct Current Motor Drive Module Positive Negative PWM Speed, Shenzhen Sijie Electronic Co., Ltd. XY-160D, Shenzhen, China), electric linear actuator (30 W/24 V, Changzhou Louie Linear Actuator Co., Ltd. BMXL250, Changzhou, China), wheel steering structure, and angular encoder (80 mA/5 V, OMRON Corporation E6B2-CWZ6C, Kyoto, Japan). The wheel independent omnidirectional steering mechanism is shown in Figure 1. The DC reduction motor drives the electric linear actuator to make a horizontal reciprocating linear motion, and then the linear motion is transformed into circumferential motion around the rotating shaft by the independent wheel bogie. The steering power transmission process is through the electric linear actuator to the independent wheel bogie and then to the steering wheel to complete the control of the wheel deflection angle. 


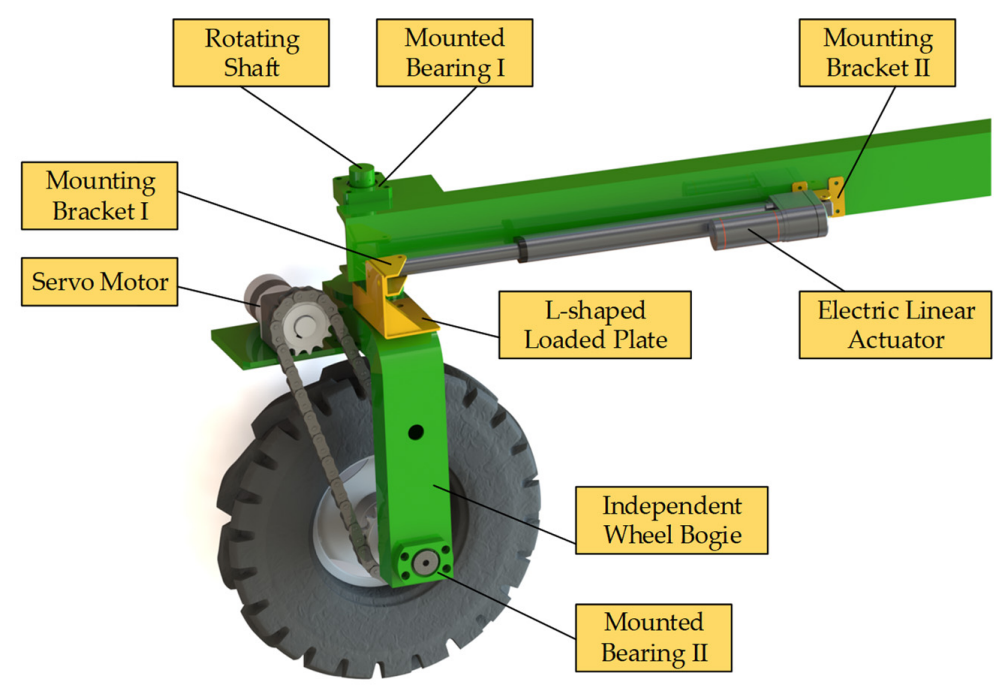

Figure 1. Wheel independent omnidirectional steering mechanism.

\subsection{Vehicle Four-Wheel Steering Kinematic Model}

The control of unmanned ground vehicles relies on the model analysis of the controlled object. This paper is mainly based on the Ackerman steering principle to construct the kinematic model of the vehicle chassis. Since the running speed of agricultural vehicles is relatively low when working in the field, it is suitable to adopt the low-speed steering mode to realize the four-wheel independent steering function of the vehicle. The four-wheel steering kinematic model [28,29] of agricultural vehicles is shown in Figure 2, which is based on the assumption that the contact between wheels and the ground is pure rolling without relative sliding. In the horizontal projection view, the chassis rotates around the instantaneous center $O^{\prime}$ point, and the turning radius $R$ changes with the degree of wheel deflection. In this steering mode, a smaller turning radius can be achieved, and the front and rear wheels of the vehicle present opposite deflection directions [30]. Furthermore, it should be set that the wheel deflection angle on the inner side is larger than that the outer side one.

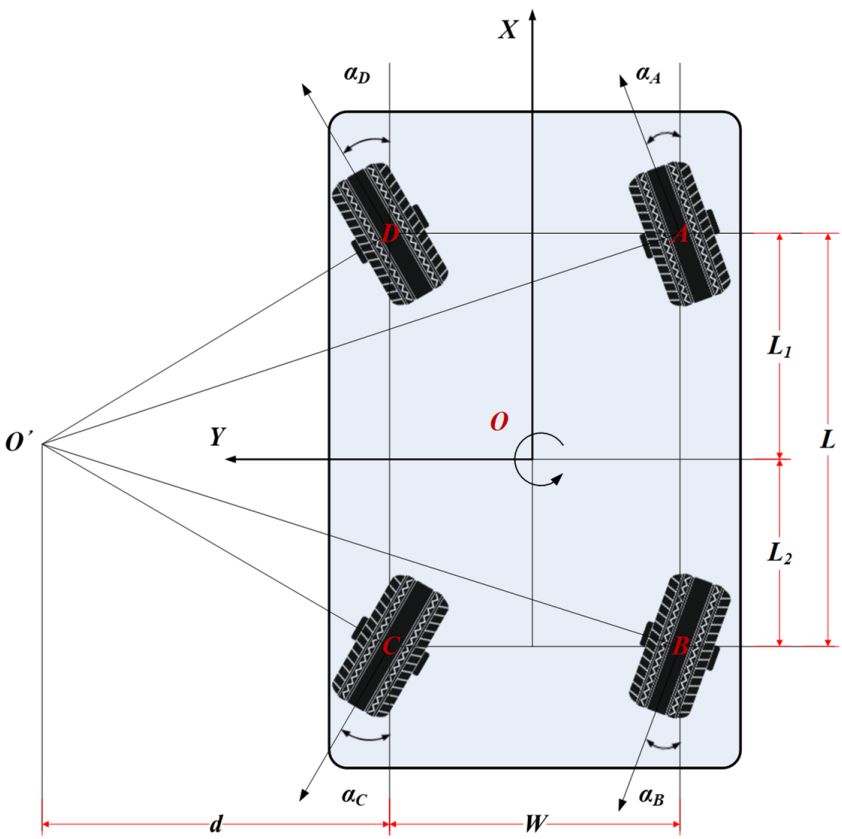

Figure 2. Vehicle four-wheel steering kinematic model. 
In Figure 2, Oxy refers to the fixed coordinate system; $O^{\prime}$ refers to instantaneous center; $W$ refers to the distance between the wheels on both sides (m); $L$ refers to the distance between the front and rear wheel axles $(\mathrm{m}) ; d$ refers to the horizontal distance from inner side wheels to instantaneous center $(\mathrm{m}) ; L_{1}$ refers to the vertical distance from front wheels to instantaneous center $(\mathrm{m}) ; L_{2}$ refers to the vertical distance from rear wheels to instantaneous center $(\mathrm{m}) ; \alpha_{i}(i=A, B, C, D)$ refers to the deflection angle of each wheel $\left(^{\circ}\right)$.

Based on the above steering model, the relationship between the deflection angle of each wheel satisfies the Ackerman steering formula [31], as shown in Equation (1).

$$
\left\{\begin{aligned}
\alpha_{A} & =\arctan \frac{L_{1}}{d} \\
\alpha_{B} & =\arctan \frac{L_{2}}{d} \\
\alpha_{C} & =\arctan \frac{L_{2}}{W+d} \\
\alpha_{D} & =\arctan \frac{L_{1}}{W+d}
\end{aligned}\right.
$$

When the rotation angles of the wheels on the same side are the same, the deflection angles of the front and rear wheels are equal in value but opposite in direction. By simplifying the above model as a two-wheeled vehicle model [32], the relationship between the deflection angles of wheels on different sides on the same horizontal axis can be described as Equation (2).

$$
\left\{\begin{array}{l}
\frac{W}{L_{1}}=\cot \alpha_{D}-\cot \alpha_{A} \\
L_{1}=\frac{W}{\cot \alpha_{D}-\cot \alpha_{A}} \\
d=\frac{W \cdot \tan \alpha_{A}}{\cot \alpha_{D}-\cot \alpha_{A}}
\end{array}\right.
$$

\subsection{Theoretical Analysis of Steering Actuator Thrust}

Agricultural vehicles need to overcome the resistance when soil structure is damaged during the process of steering in the field. When the independent steering mechanism is subjected to steering resistance, in order to clarify the thrust force of the piston rod to push the wheel steering, the mechanical analysis of the steering actuator is carried out. The thrust of the actuator mainly depends on the contact resistance between the tire and the soil when each wheel deflects under the steering operation state of the agricultural vehicle. The thrust expression of the piston rod satisfies Equation (3). It can be seen from this equation that the calculation of thrust value is mainly related to the parameters such as piston rod lead, linear velocity and rotating rate. The lead value of the piston rod is determined by the linear velocity and rotating rate of the piston rod, which are required during wheel deflection. Furthermore, combined with the relevant parameters of the motor and reducer, the thrust value of the electric linear actuator can be finally obtained.

$$
\left\{\begin{array}{l}
l=\frac{v \cdot 60}{n_{a}} \\
F=\frac{T \cdot \eta \cdot 2 \pi \cdot R_{a}}{l}
\end{array}\right.
$$

where $l$ is piston rod lead $(\mathrm{mm}) ; v$ is the linear velocity of the piston $\operatorname{rod}\left(\mathrm{mm} \cdot \mathrm{s}^{-1}\right) ; n_{a}$ is the rotation rate $\left(\mathrm{r} \cdot \mathrm{min}^{-1}\right) ; F$ is the thrust of the electric linear actuator $(\mathrm{kN}) ; T$ is motor torque $(\mathrm{N} \cdot \mathrm{m}) ; \eta$ is the comprehensive transmission efficiency; $R_{a}$ is the reduction ratio.

In addition, according to the relationship curve of the rated stroke, load and rotation rate of the electric linear actuator (as shown in Figure 3), it can be checked whether the rotation rate of the electric linear actuator satisfies the requirement of $80 \%$ of the dangerous speed, and determine the effective stroke amount of the piston rod so as to prepare for the subsequent analysis of the wheel deflection dynamic model. 


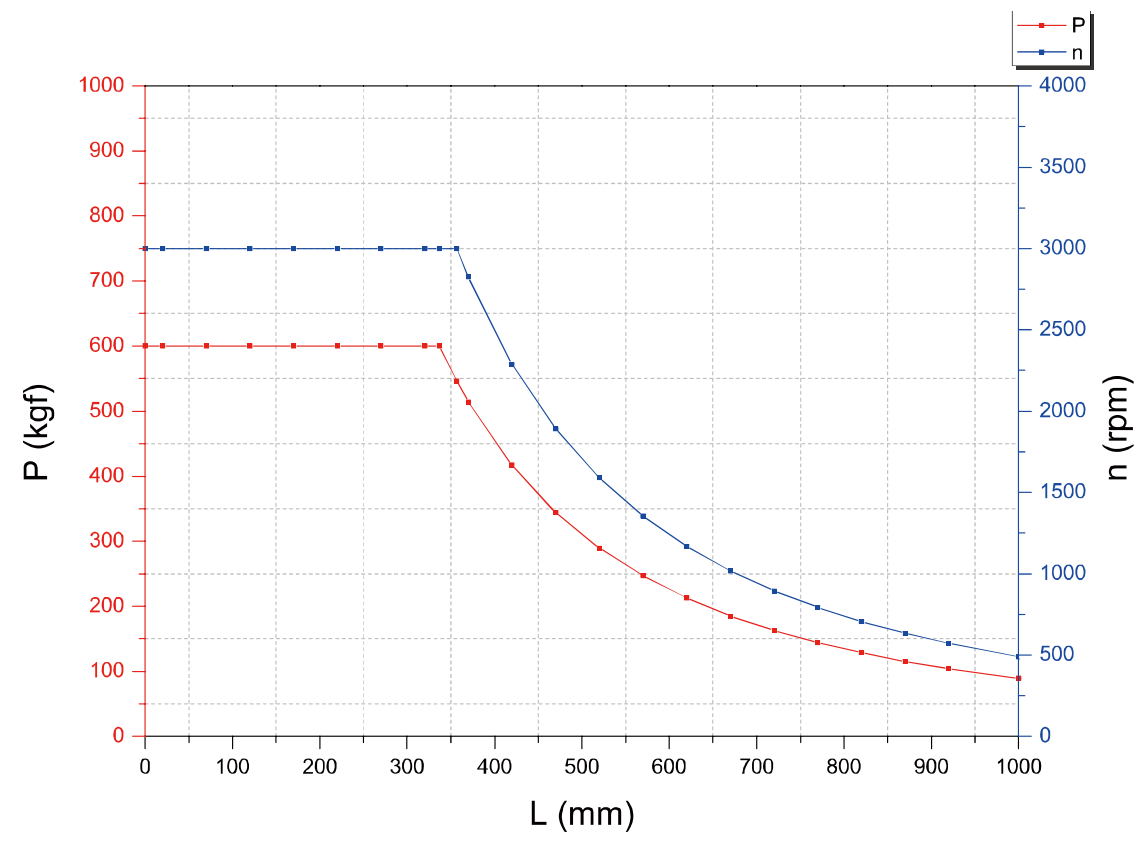

Figure 3. Relationship curve of rated stroke, load and rotation rate of electric linear actuator.

\section{Control System Design}

\subsection{Wheel Deflection Control System Design}

Based on the two core components of the SCM controller and L298 motor drive module, a software platform for the deflection control system was established. The proposed platform will simultaneously drive four electric linear actuators to complete the wheel deflection target by controlling the transmission of motion instructions. By controlling the start, end, forward and reverse rotation of the motor, the reciprocating linear motion of the piston rod is realized, and the stroke of the piston rod can be accurately controlled through the pulse width modulation (PWM) speed control method, which also means that the angular deflection of the wheels can also be controlled synchronously. The hardware circuit of the detection control system is shown in Figure 4. Specifically, when the SCM controller receives the wheel deflection angle detected by the angular encoder, according to the linear relationship between the movement displacement of the piston rod and the wheel deflection angle, the piston rod will extend or contract a certain displacement according to the feedback adjustment value to drive the independent wheel bogie to make a clockwise or counter-clockwise deflection movement. The SCM controller can ensure the precise correspondence between the piston rod stroke and the wheel deflection angle by collecting the pulses feedback from the built-in encoder. When the encoder of the electric linear actuators sends 16 pulses, the piston rod can make one revolution, and the accuracy of pulses is mainly detected and guaranteed by the Hall-effect sensor.

The algorithm flow chart of the deflection control system is shown in Figure 5. After starting the operation switch, the system will first judge whether the motor has completed initialization. If it has not been initialized, there is a risk that the origin of the motor is not at the intermediate point, so it sets the re-adjustment process and then re-starts working again. If the initialization is completed, the angular encoder is ready to start collecting the wheel deflection angle signal, and the offset distance of the piston rod is calculated by the upper computer and sends control instructions to the SCM. The SCM controller is responsible for obtaining the forward speed of the agricultural vehicle and completing the corresponding calculation. Finally, the motion parameters are sent to the electric linear actuator, after which the angular encoder continues to collect the new wheel deflection angle and executes the process again. 


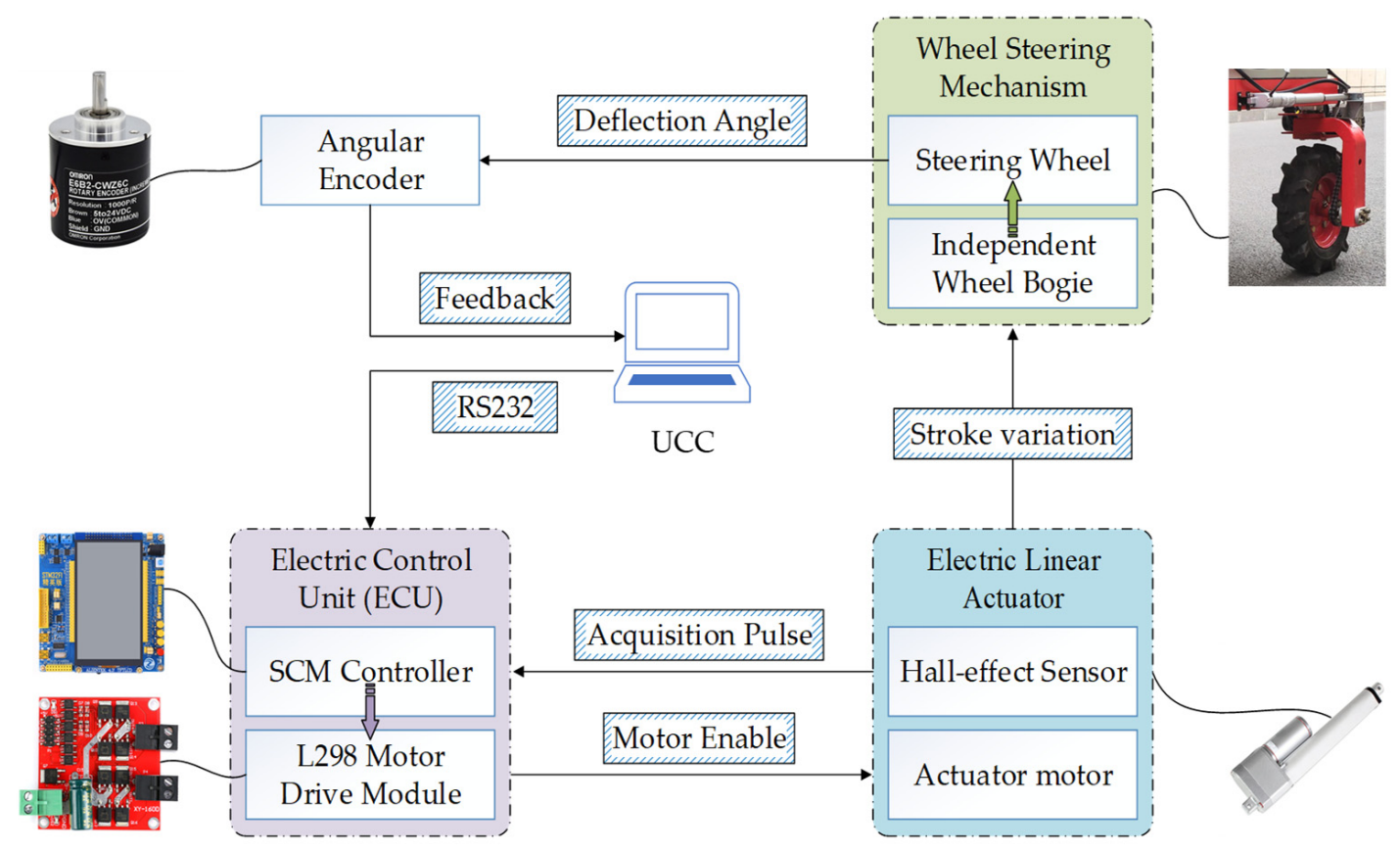

Figure 4. Hardware architecture of deflection control system.

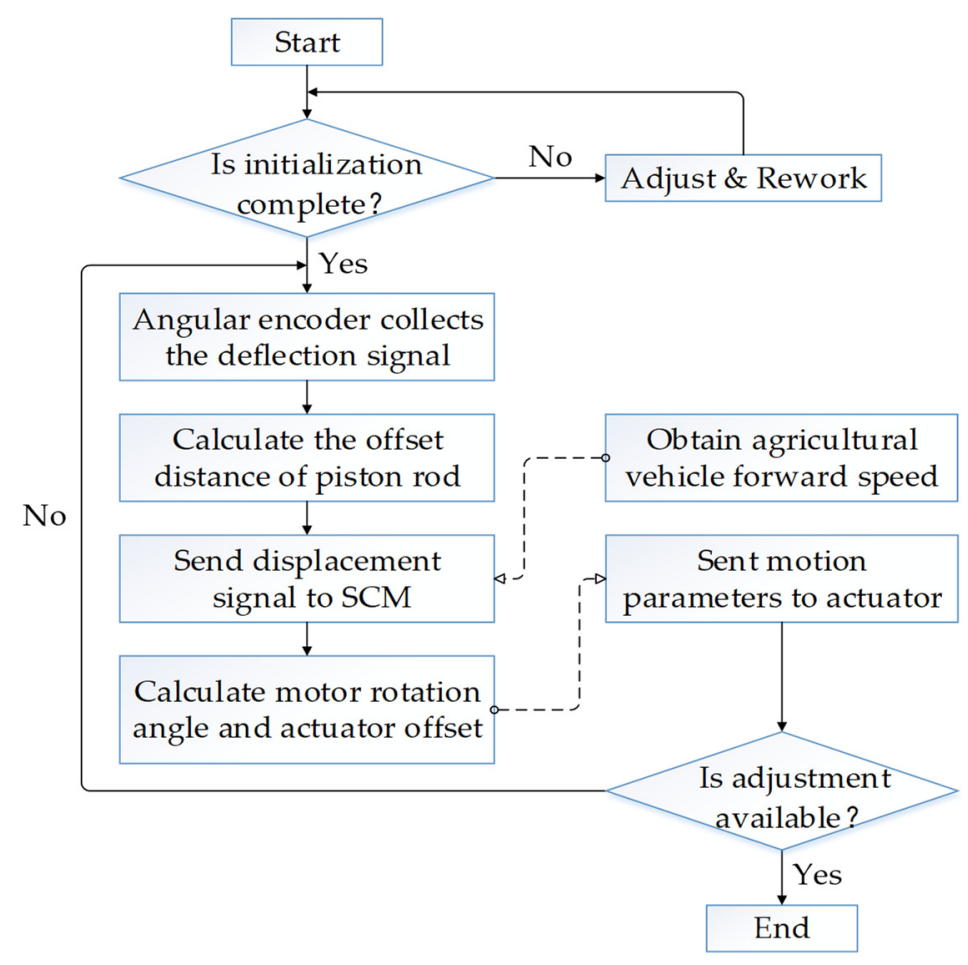

Figure 5. Algorithm flow chart of deflection control system.

\subsection{Wheel Deflection Controller Design}

\subsubsection{Fuzzy PID Algorithm Structure Design}

PID control is a linear controller based on error feedback, which outputs the deviation value to the actuators through proportional, integral and differential (PID) processing to realize the control of the system. Its control law is expressed in Equation (4). If the input signal of the system is discretized, the incremental PID control formula can be obtained as in Equation (5). This control algorithm only outputs the incremental part of the control 
variable without accumulation, so it is suitable for this paper with its characteristics of small calculation error and high precision [33]. Fuzzy control is a kind of nonlinear control method without an accurate mathematical model, which makes fuzzy reasoning on the input variables after fuzzification according to the designed fuzzy control rules, and then outputs accurate controlled variables through defuzzification.

$$
\begin{gathered}
u(t)=K_{p}\left[e(t)+\frac{1}{T_{i}} \int_{0}^{t} e(t) d t+T_{d} \frac{d e(t)}{d t}\right] \\
\triangle u(k)=K_{p}[e(k)-e(k-1)]+K_{I} e(k)+K_{D}[e(k)-2 e(k-1)+e(k-2)]
\end{gathered}
$$

where $u(t)$ is the output control signal; $K_{P}$ is the proportional gain; $e(t)$ is the input deviation control signal; $T_{i}$ is the integration time; $T_{d}$ is derivative time; $\Delta u(k)$ is an increment of the output control signal; $K_{I}$ is the integral coefficient; $K_{D}$ is the differential coefficient.

The fuzzy PID control adopted in this paper is a fuzzy logic control structure with two inputs, three outputs and 49 rules. The lateral deviation $e$ and deviation variation $e c$ of the agricultural vehicle are taken as input variables, and the parameters $K_{P}, K_{I}$ and $K_{D}$ after online adjustment are taken as output variables. These parameters are synthesized by linear relationship to the controlled variable $u$ and then transmitted to the steering actuator. The fuzzy PID structure of the deflection control system is shown in Figure 6.

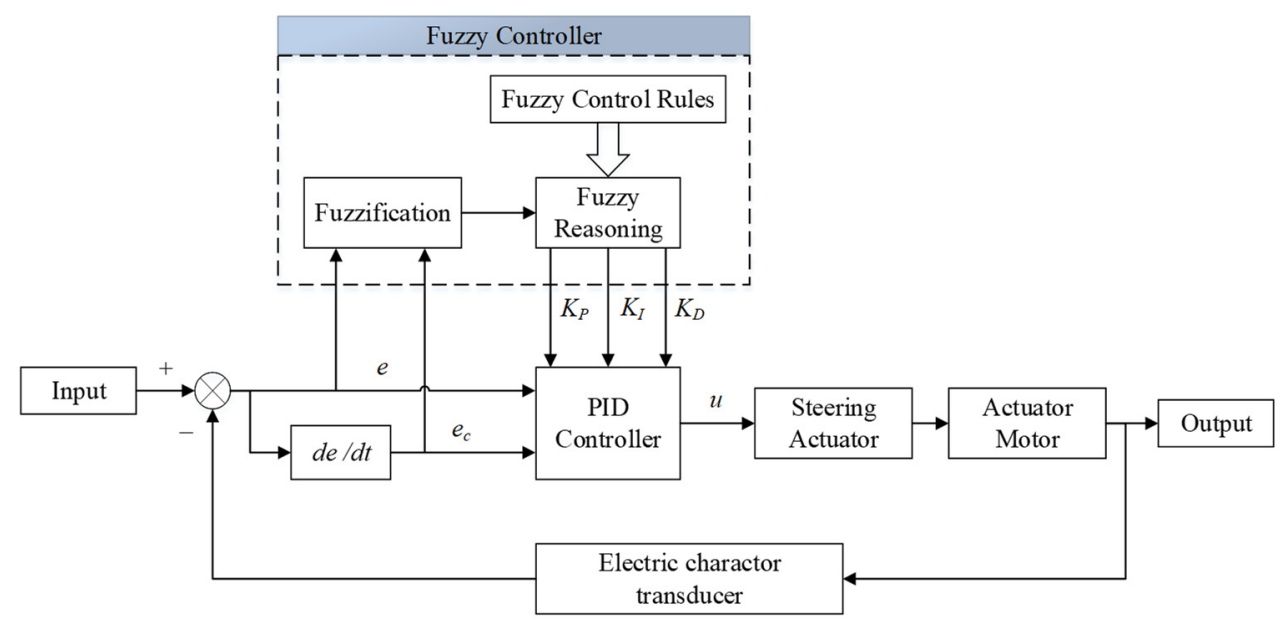

Figure 6. Fuzzy PID control structure of deflection control system.

\subsubsection{Fuzzy PID Controller Design}

Taking the transverse distance error between the linear tracking path and the target path as the control object, using the lateral deviation $e$, which is between the target value and the feedback value, and the deviation rate $e c$ as the input variables of the controller, then taking the rotation angle value $u$ of the electric linear actuator's motor as the output variable of the controller, a fuzzy PID controller is designed eventually. Set the forward direction of the agricultural vehicle as negative on the left and positive on the right, and set the fuzzification process to be described by seven linguistic variables, all of which are (NB (negative large), NM (negative middle), NS (negative small), ZO (zero), PS (positive small), PM (positive medium), PB (positive large). The membership function curves of two input variables and three output variables are shown in Figure 7, and the three-dimensional output surface of the fuzzy control variables $K_{P}, K_{I}, K_{D}$ are shown in Figure 8 . The fuzzy control rules of proportionality coefficient $\Delta K_{P}$, integration coefficient $\Delta K_{I}$ and differential coefficient $\Delta K_{D}$ are established, respectively, as shown in Tables 1-3. 


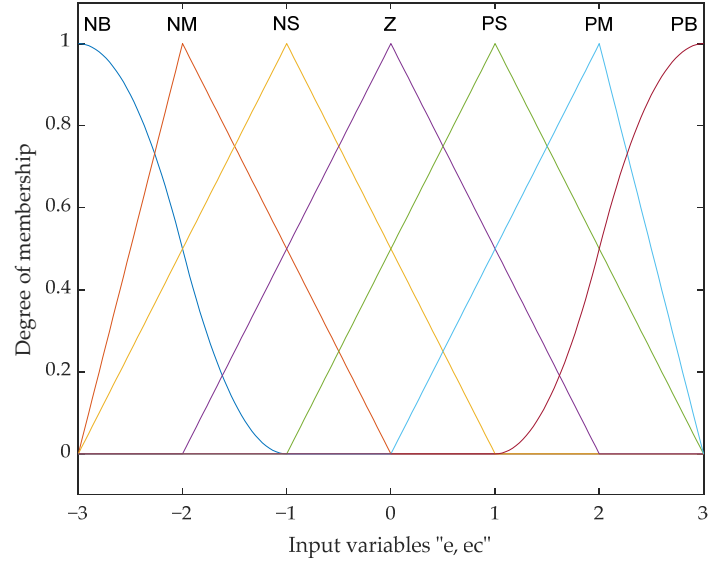

(a)

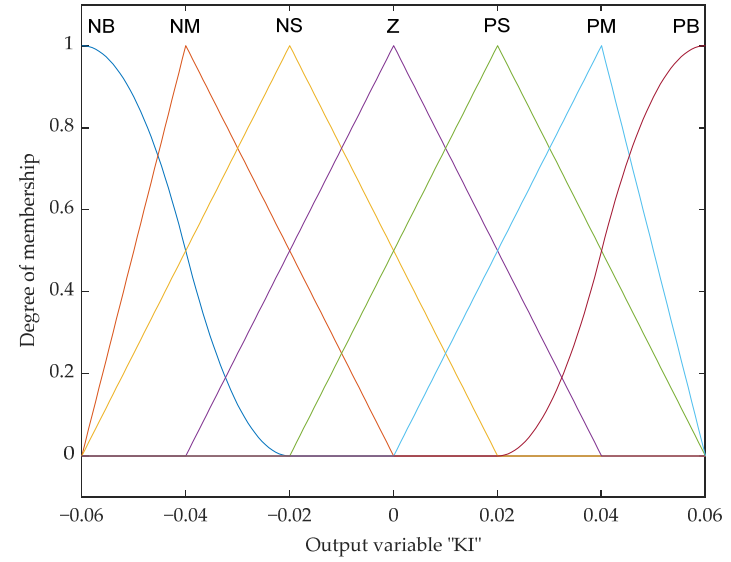

(c)

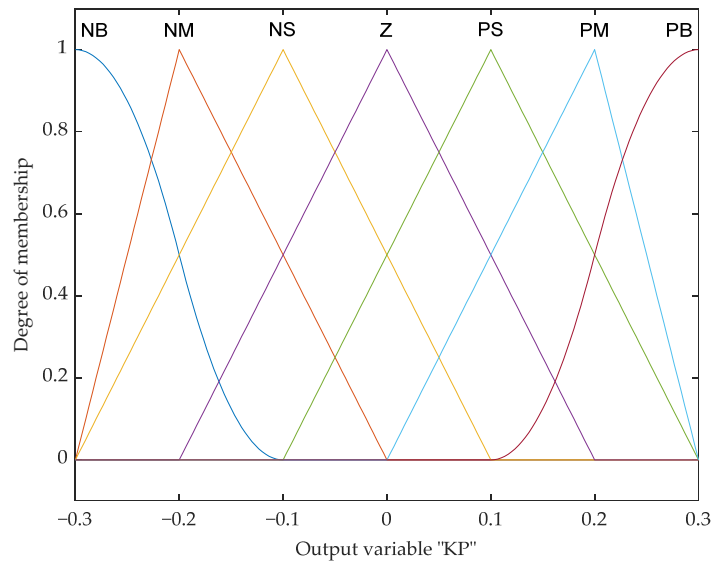

(b)

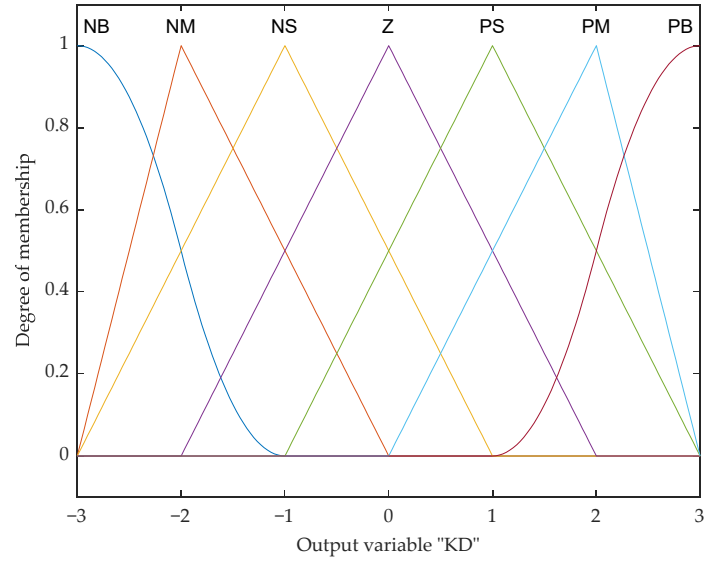

(d)

Figure 7. The membership function curves of two input variables and three output variables: (a) Input variables $e$ and $e c$; (b) Output variable $K_{P} ;(\mathbf{c})$ Output variable $K_{I} ;(\mathbf{d})$ Output variable $K_{D}$.

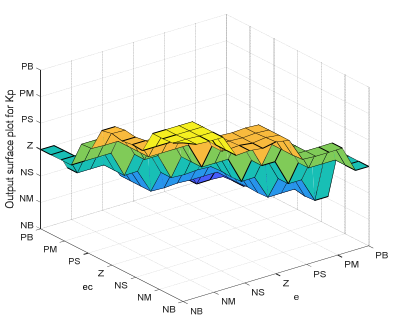

(a)

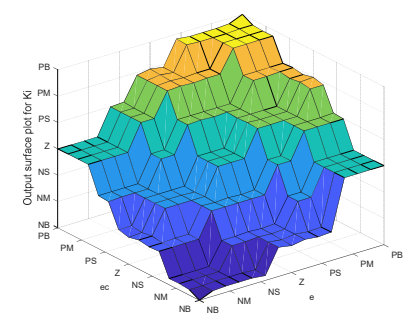

(b)

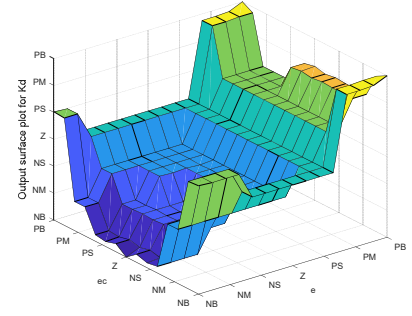

(c)

Figure 8. The three-dimensional output surface of the fuzzy control output variables: (a) $K_{P}$ output surface; (b) $K_{I}$ output surface; (c) $K_{D}$ output surface. 
Table 1. $\Delta K_{P}$ fuzzy control rules.

\begin{tabular}{ccccccccc}
\hline \multirow{2}{*}{$\boldsymbol{\Delta} \boldsymbol{K}_{\boldsymbol{P}}$} & \multicolumn{7}{c}{$\boldsymbol{e c}$} \\
\cline { 2 - 8 } & & NB & NM & NS & ZO & PS & PM & PB \\
\hline \multirow{4}{*yyyyyyyy}{} & NB & PB & PB & PM & PM & PS & ZO & ZO \\
& NM & PB & PB & PM & PS & PS & ZO & NS \\
& NS & PM & PM & PM & PS & ZO & NS & NS \\
& ZO & PM & PM & PS & ZO & NS & NM & NM \\
& PS & PS & PS & ZO & NS & NS & NM & NM \\
& PM & PS & ZO & NS & NM & NM & NM & NB \\
& PB & ZO & ZO & NM & NM & NM & NB & NB \\
\hline
\end{tabular}

Table 2. $\Delta K_{I}$ fuzzy control rules.

\begin{tabular}{ccccccccc}
\hline \multirow{2}{*}{$\Delta \boldsymbol{K}_{\boldsymbol{I}}$} & \multicolumn{7}{c}{$\boldsymbol{c c}$} \\
\cline { 2 - 8 } & & NB & NM & NS & ZO & PS & PM & PB \\
\hline \multirow{6}{*}{} & NB & NB & NB & NM & NM & NS & ZO & ZO \\
& NM & NB & NB & NM & NS & NS & ZO & ZO \\
& NS & NB & NM & NS & NS & ZO & PS & PS \\
& ZO & NM & NM & NS & ZO & PS & PM & PM \\
& PS & NM & NS & ZO & PS & PS & PM & PB \\
& PM & ZO & ZO & PS & PS & PM & PB & PB \\
& PB & ZO & ZO & PS & PM & PM & PB & PB \\
\hline
\end{tabular}

Table 3. $\Delta K_{D}$ fuzzy control rules.

\begin{tabular}{ccccccccc}
\hline \multirow{2}{*}{$\Delta \boldsymbol{K}_{\boldsymbol{D}}$} & \multicolumn{7}{c}{$\boldsymbol{c c}$} \\
\cline { 2 - 8 } & & NB & NM & NS & ZO & PS & PM & PB \\
\hline \multirow{6}{*}{} & NB & PS & NS & NB & NB & NB & NM & PS \\
& NM & PS & NS & NB & NM & NM & NS & ZO \\
& NS & ZO & NS & NM & NM & NS & NS & ZO \\
& ZO & ZO & NS & NS & NS & NS & NS & ZO \\
& PS & ZO & ZO & ZO & ZO & ZO & ZO & ZO \\
& PM & PB & PS & PS & PS & PS & PS & PB \\
& PB & PB & PM & PM & PM & PS & PS & PB \\
\hline
\end{tabular}

The input and output variables of the control system are described as follows:

1. The quantitative domain of lateral deviation $e$ and deviation change rate $e c$ is: $e, e c=\{-3,-2,-1,0,1,2,3\}$;

2. The quantitative domain of proportionality coefficient $\Delta K_{P}$ is: $\Delta K_{P}=\{-0.3,-0.2$, $-0.1,0,0.1,0.2,0.3\}$;

3. The quantitative domain of integration coefficient $\Delta K_{I}$ is: $\Delta K_{I}=\{-0.06,-0.04,-0.02$, $0,0.02,0.04,0.06\}$;

4. The quantitative domain of differential coefficient $\Delta K_{D}$ is: $\Delta K_{D}=\{-3,-2,-1,0,1,2,3\}$.

\section{Control System Simulation Analysis}

\subsection{Dynamic Simulation of Wheel Deflection}

In this paper, the wheels are individually driven by an electric linear actuator, but the initial stroke position of the actuator does not have an optimal solution, so it is impossible to judge whether the steering angle exceeds the allowable deflection threshold of the piston rod lead range. Within the allowable variation range of the installation position, in order to minimize the thrust value during the wheel deflection process, the installation position of the electric linear actuator on the channel steel needed to be optimized [34].

This paper uses Solidworks software to build a virtual three-dimensional model of the steering mechanism and then import it into the ADAMS dynamic simulation software. 
However, there is only one relative position relationship between each object, so it is necessary to manually and empirically add some constraint pairs, loads and drives to limit its freedom. These constraints are added according to the actual motion state and constraint relationship. Specifically, the processing operations mainly include adding 5 rotary joints, 12 fixed joints and 1 mobile joint. Then, apply the constant linear velocity thrust obtained from Section 2.3 to the piston rod and also add an angle encoder to the wheel bogie. The runtime function of the speed joint motion is:

step (time, 0, 0, 0.1, 50) + step (time, 1.6, 0, 1.8, -100).

When constraints are established between components, marker points will be automatically generated to determine the position of constraint pairs. The simplified steering mechanism model in the ADAMS simulation environment is shown in Figure 9.

The interactive simulation solver was used in the simulation process, setting the simulation time as $5 \mathrm{~s}$ and the number of simulation steps of 1000. Then, also take the displacement variable and thrust variable of the piston rod as the simulation objects. The motion characteristic curves were obtained as shown in Figure 10. Through the simulation result of the response curve in the figure, the different values of the thrust force during the change of piston rod displacement can be roughly described. (1) According to the regulations, the left deflection angle of the wheel is positive, and the right deflection angle is negative. First of all, it can be seen from the blue dotted line that within the set simulation time, the displacement length of the electric linear actuator is shortened first and then extended. This means that under the push of the actuator, the wheel deflection movement is to turn left for a certain angle and then return to the opposite direction after $1.7 \mathrm{~s}$. (2) While the red curve reflects the fluctuation situation of the piston rod thrust. When the simulation time is around $1.7 \mathrm{~s}$, the thrust value increases obviously because when the wheel deflection direction changes suddenly, the steering resistance will have an obvious step increase. After the transition, the changing amplitude of thrust value will decrease gradually. In this process, the minimum value of piston rod thrust is located at the time of $1.6 \mathrm{~s}$, which is the moment before the sudden change in the direction of the wheel. (3) According to the moment when the minimum thrust force appears, the corresponding displacement length of the electric push rod is determined to be $233 \mathrm{~mm}$ in the figure. This length represents the initial displacement length between the actuator fixed point and the channel steel head. In this state, the minimum solution of the thrust value for wheel deflection is satisfied.

In view of the above analysis and the limitation of the practical installation space, a horizontal distance of $233 \mathrm{~mm}$ is set on the channel steel as the initial installation position of the electric linear actuator. Thus, the feasibility and rationality of the wheel steering mechanism are verified. At the same time, it can also provide reference and theoretical basis for the design, experiment and improvement of the wheel steering mechanism. 


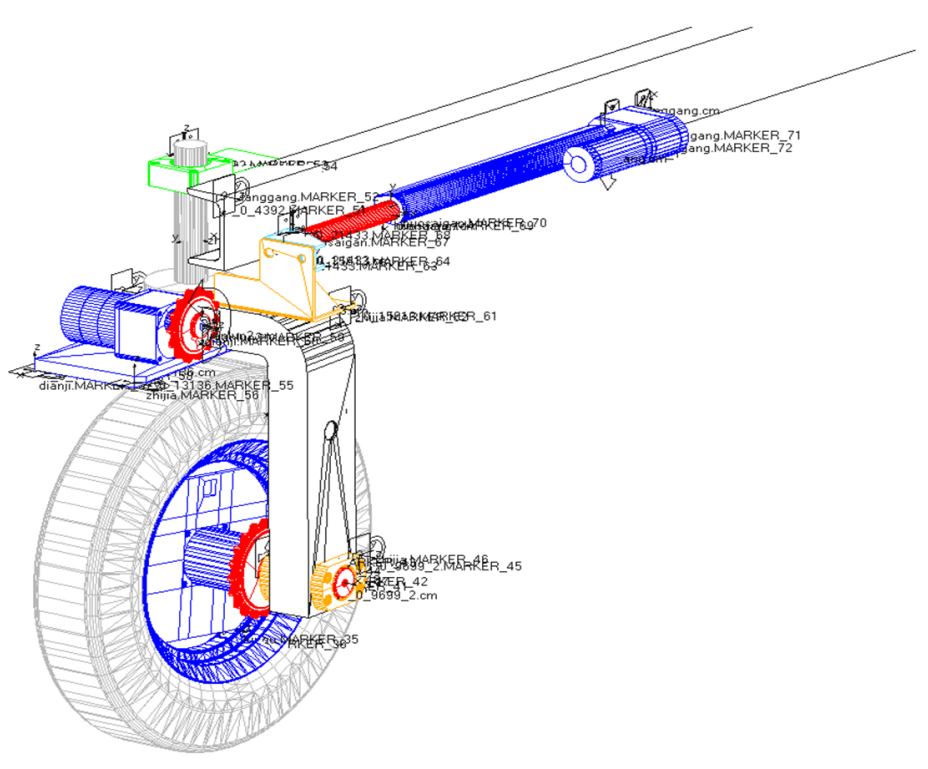

Figure 9. ADAMS simulation model of steering mechanism.

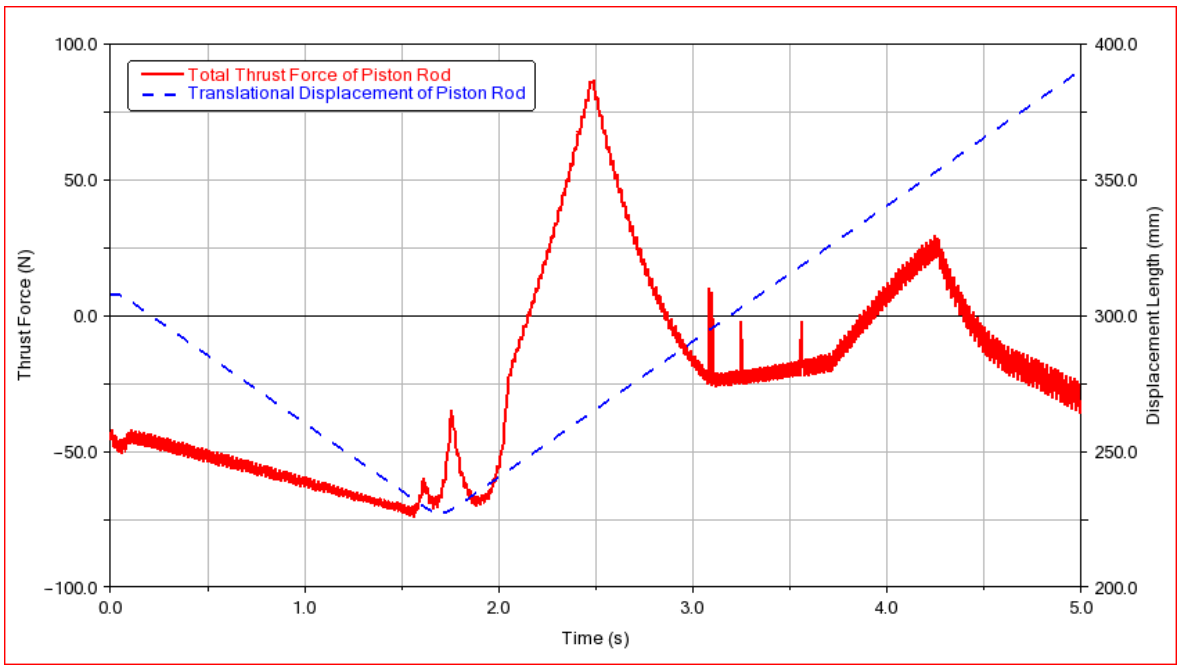

Figure 10. Simulation characteristic curves: the blue dotted curve reflects the transitional displacement of the piston rod; the red curve reflects the total thrust force of the piston rod.

\subsection{Wheel Deflection Controller Simulation}

The fuzzy PID controller proposed in Section 3.2.2 is applied to the wheel deflection control system of agricultural vehicle, and the simulation model of the system is established based on the Matlab/ Simulink simulation environment, as shown in Figure 11, which verifies the performance and adaptability of the proposed fuzzy PID control method. 


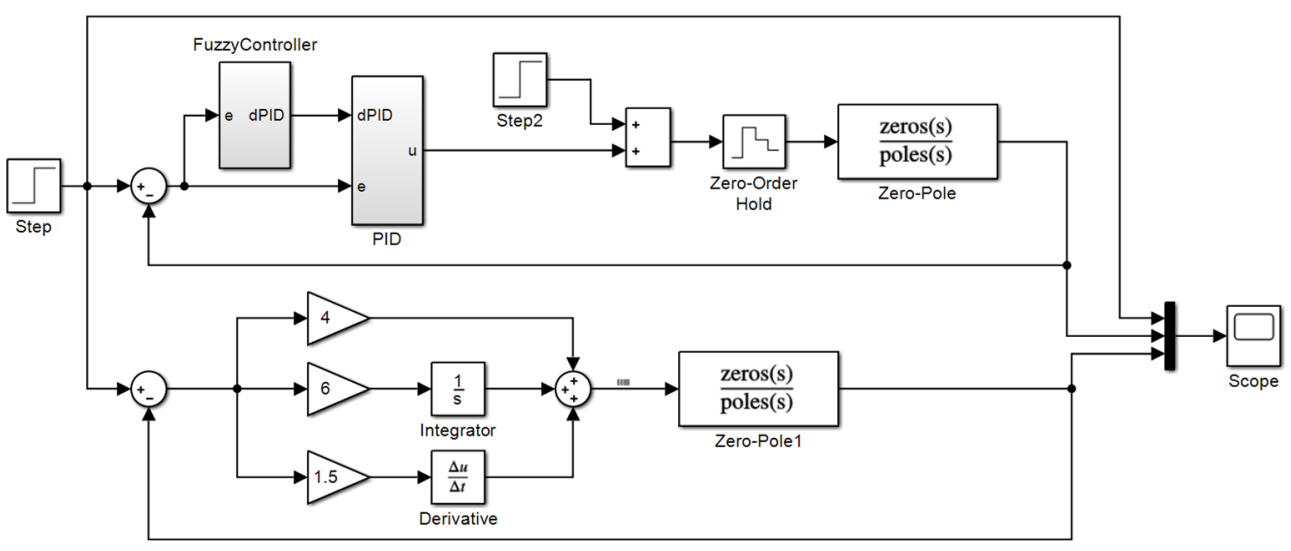

(a)

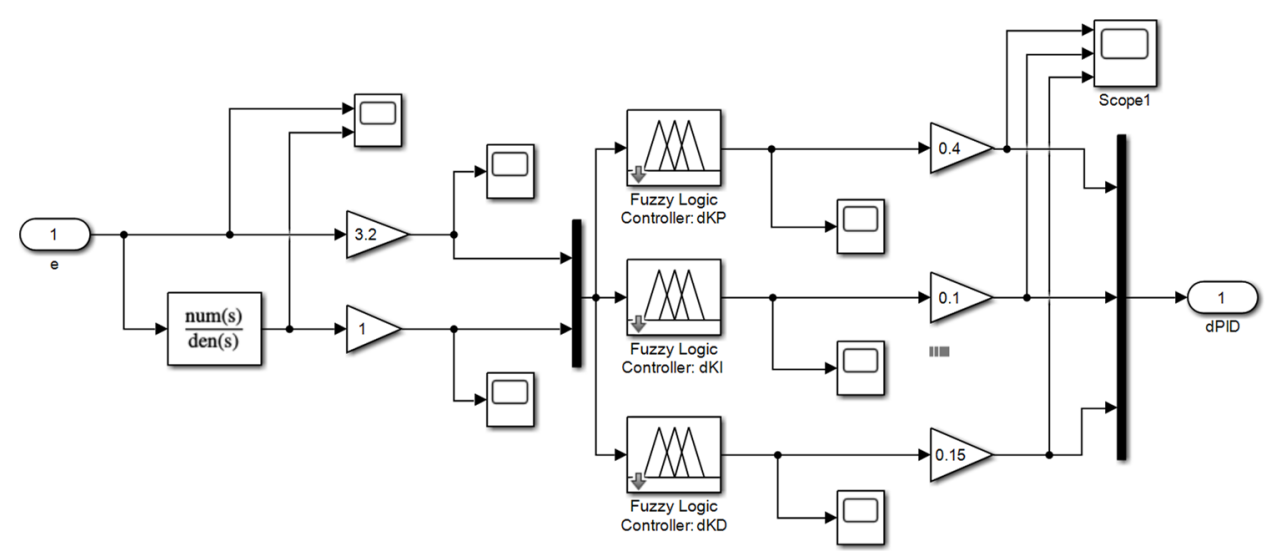

(b)

Figure 11. Simulation model of fuzzy PID deflection control system: (a) Comparative simulation model between Fuzzy PID controller and traditional PID; (b) Fuzzy controller simulation model.

Due to the harsh working environment of agricultural vehicles in the field, it is difficult to establish an accurate mathematical model, so the method of combining the critical proportioning method [35] and cut-and-trial method is used to adjust the parameters of the system. First of all, the cut-and-trial method is used to preliminarily determine the value range of the three parameters, following the basic principle of adjusting the proportionality coefficient $K_{P}$ first, then the integral coefficient $K_{I}$, and finally adjusting the differential coefficient $K_{D}$. Combing with the overshoot, response speed and system stability reflected by the response curve, then make a preliminary judgment on the effects of system stability and other effects. Then increase the proportionality coefficient $K_{P}$ value gradually, taking the $K_{P}$ value when the system occurs oscillation and the time between two peaks of a wave and further determine the parameter value according to the parameter adjustment rules of the critical proportioning method, and finally set the initial values of three parameters $K_{P}, K_{I}$ and $K_{D}$ as: $K_{P 0}=4, K_{I 0}=6$ and $K_{D 0}=1.5$, respectively. In addition, the quantization factors of the input variables $e$ and $e c$ are selected to be 3.2 and 1, respectively, and the scale factors of the output variables are $0.4,0.1$ and 0.15 , respectively.

Set the model transfer function of the controlled object, as shown in Equation (6), and discretize it by Z-transform. During the simulation, set the sampling time as $1 \mathrm{~ms}$, input step signal with an amplitude of 1 and sinusoidal signal with an amplitude of 1 and frequency of $1 \mathrm{rad} / \mathrm{s}$, respectively, and add $1.0 \mathrm{~V}$ interference signal in $0.3 \mathrm{~s}$ to track the 
position of step signal and sinusoidal signal, respectively. The simulation test results are shown in Figure 12.

$$
G(s)=\frac{\operatorname{zero}(s)}{\operatorname{poles}(s)}=10 \cdot \frac{s+0.5}{(s+1)^{3}}
$$

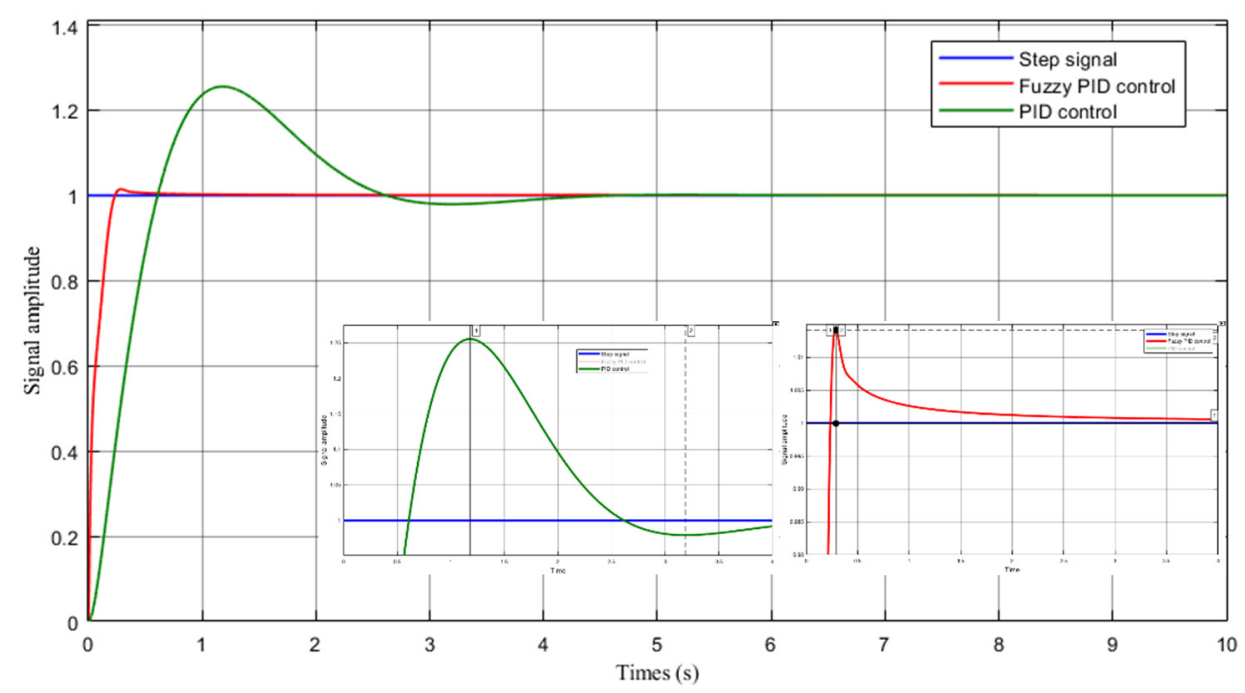

Figure 12. Simulation response curve of control system: Step signal tracking simulation.

From the simulation waveform of the step response curve in Figure 12, it can be seen that the rise time of the fuzzy PID control response curve is $0.3 \mathrm{~s}$, the maximum overshoot is $1.5 \%$ and the adjustment time is $1.7 \mathrm{~s}$. The PID control response curve rise time is $1.2 \mathrm{~s}$, the maximum overshoot is $25.9 \%$ and the adjustment time is $5.2 \mathrm{~s}$. The adjustment time of PID control lags behind that of fuzzy PID control by $3.5 \mathrm{~s}$, and the maximum signal tracking error amplitude of the former is about 0.25 , while the maximum signal tracking error amplitude of the latter is about 0.02 .

The simulation results show that the optimized fuzzy PID control algorithm has the following advantages over the conventional PID control algorithm:

1. Shorter transition time;

2. Faster response speed;

3. Smaller steady-state error;

4. The system overshoot is greatly reduced.

In conclusion, the use of fuzzy PID control algorithm can improve the dynamic performance of the control system. It can better meet the control requirements of wheel steering in the process of agricultural vehicle linear tracking.

\section{Verification of Linear Path Walking Test}

\subsection{Development Test Platform}

The wheel steering control platform in this study mainly uses SCM as the main controller and a personal computer (PC) as the upper terminal for measuring and controlling the test program. In addition, the SCM controller is also used to receive the actual wheel deflection angle signal fed back by the angle encoder for closed-loop control. The controller area network (CAN) analyzer is used as a relay system to configure and transmit CAN signals through the USB-CAN Tools while monitoring the commands sent by the main controller to the driver in real-time. Moreover, the L298 motor drive module is mainly used to drive the electric linear actuator to realize the left and right turn, and the precise stroke of the piston rod is controlled by the PWM method. In addition, the current communication data and feedback information can be displayed on the control program interface on the PC. 


\subsection{Linear Path Walking Test}

In order to verify the path walking performance of the control system described in this paper, a linear path test was carried out on a dry cement road and field road. The test takes a self-propelled agricultural mobile platform as the object, which is especially suitable for small plot farmland or facility agriculture. The real test control platform is shown in Figure 13. Then record the path walking of the vehicle when driving in a straight line and verify the lateral deviation and yaw angle error of the vehicle. The control program is implemented based on the integrated development environment Keil U5 and then burned the fuzzy PID control program into the SCM controller. The L298 motor drive module activates the movement of the electric linear actuator so as to promote the wheel deflection control system to start adjustment.

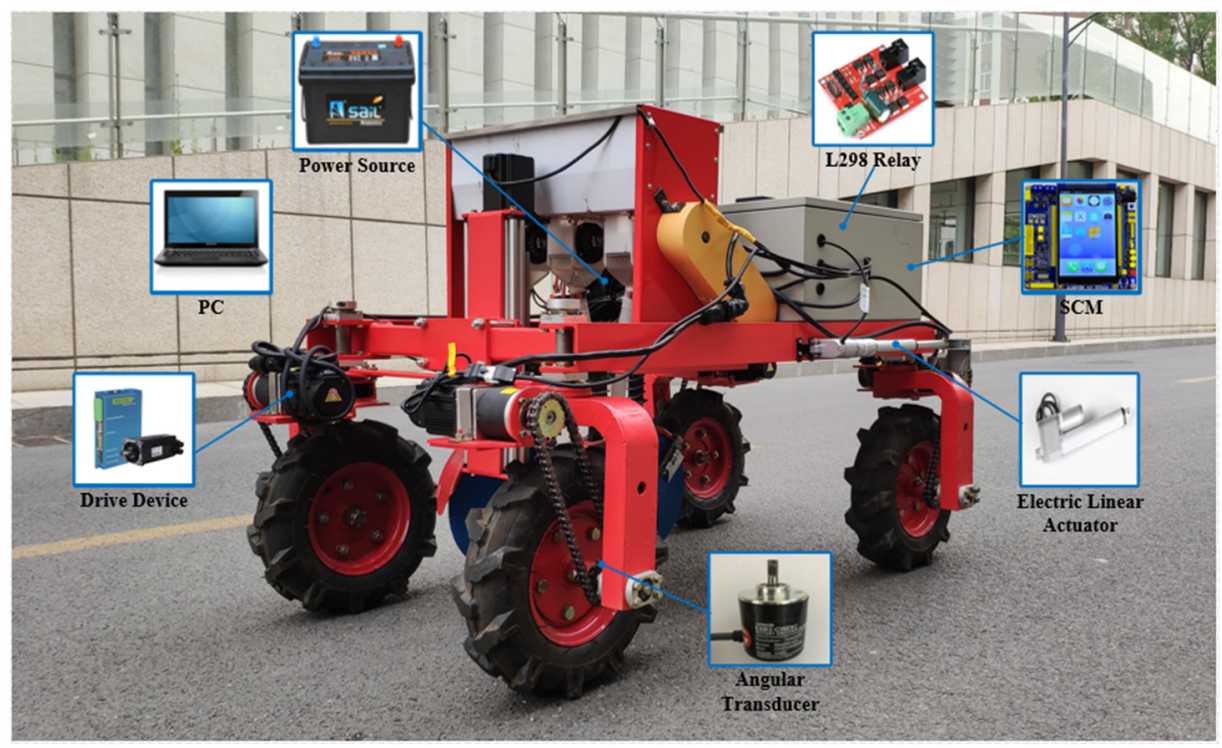

(a)

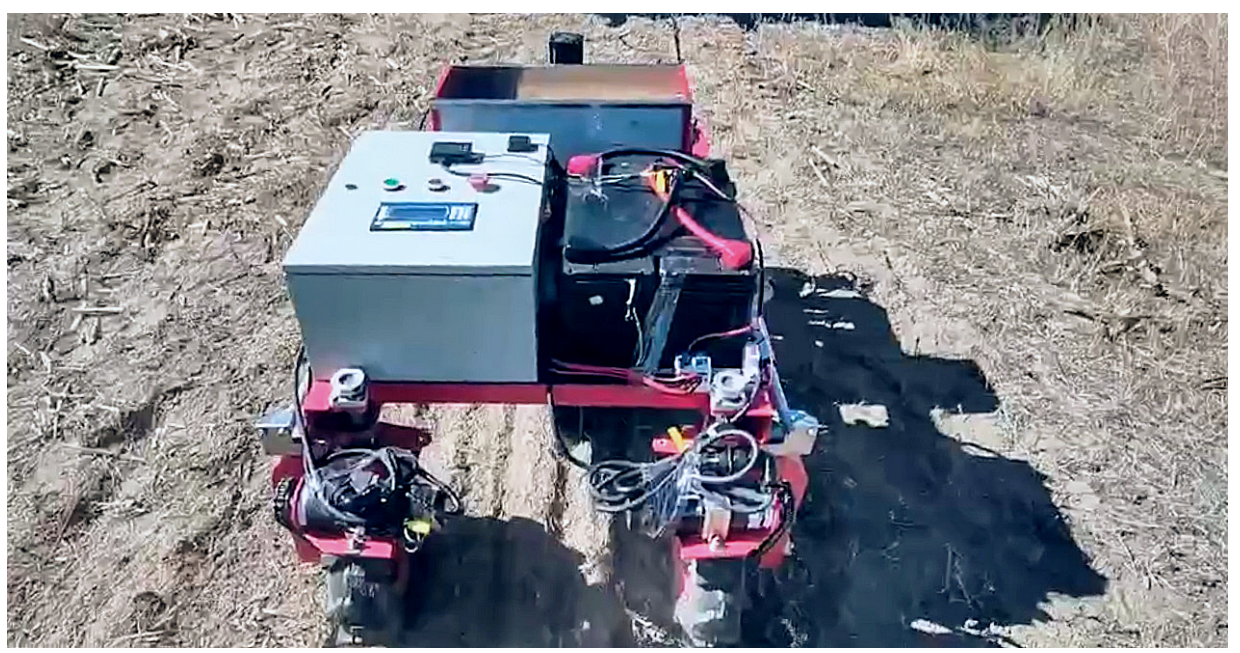

(b)

Figure 13. Practical linear path walking test: (a) on dry cement road; (b) on field road.

\subsection{Results and Discussion}

Because this paper adopts a four-wheel independent omnidirectional steering control system, each wheel can deflect in a large range and even realize in situ rotary movement. Therefore, this test is used to verify whether the agricultural vehicle can basically follow 
the predetermined path. Setting the driving speed of the agricultural vehicle to $1 \mathrm{~m} / \mathrm{s}$, and the straight-line tracking error is mainly measured by the traces of the tire on the ground. The real test control curve is shown in Figure 14. It can be seen from the test results, the lateral deviation of the vehicle rapidly decreases at first and then tends to be stable at about $0.15 \mathrm{~s}$. After gradually stabilizing, the path tracking error fluctuates within $1.5 \mathrm{~cm}$, and the average tracking error is about $2.7 \mathrm{~cm}$. The test results show that the proposed fuzzy PID controller for the wheel deflection control system has better control performance, which meets the deviation control requirements between the actual path and the target path in the process of automatic driving.

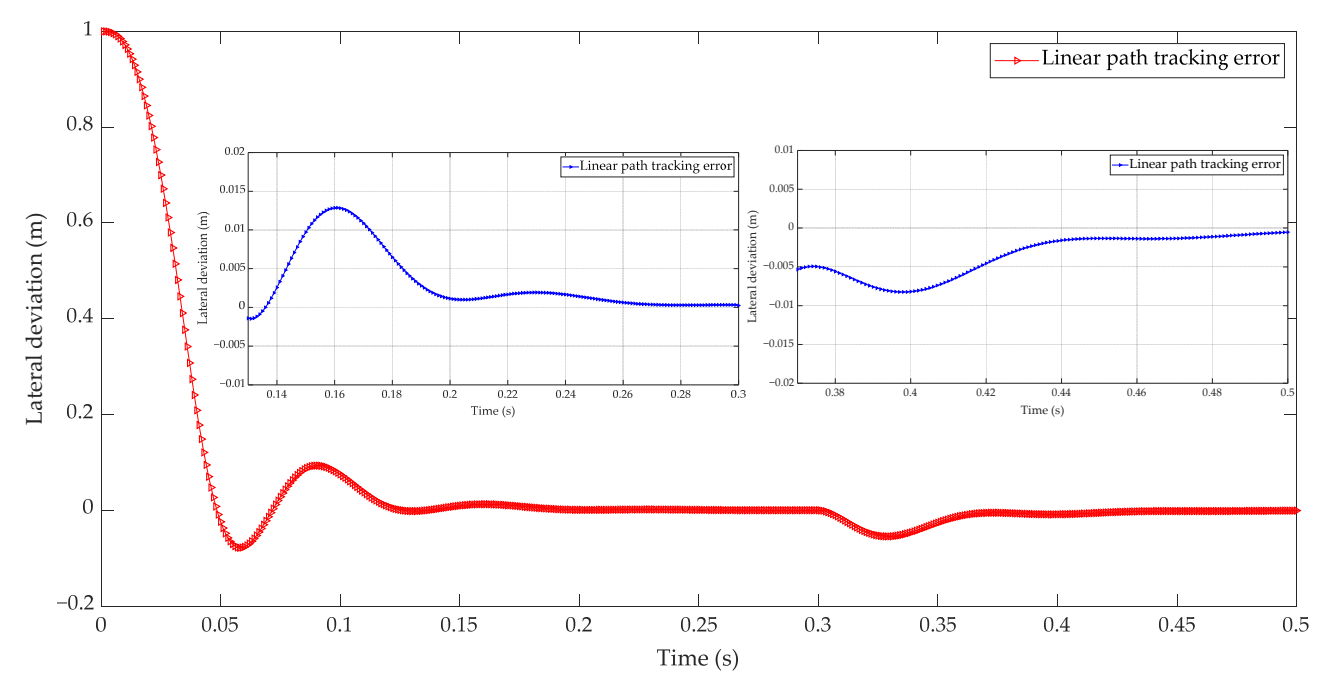

Figure 14. Lateral deviation control curve of linear path tracking.

In order to detect the control accuracy of the four-wheel independent steering control system, the error measurement between the practical deflection value and the set deflection value is measured on the field ground. The practical angle value is obtained through the angle encoder feedback, and each group of parameters is repeatedly measured 10 times [31]. While the set angle value is manually input by the host computer. After each set angle is given, a corresponding practical angle value will be obtained. When the wheel deflection angle is small, the executive command sent by the SCM controller can be directly transformed into the displacement of the electric linear actuator to make the steering wheel follow the movement according to the set angle value.

In the process of controlling the wheel to achieve left-right deflection, the relationship between the displacement length of the piston rod and the deflection angle of the wheel is shown in Figure 15. In the linear fitting curve of the two parameters, the R-squared value is 0.9996 , which is approximately equal to 1 , reflecting the close correlation between the two variables of the abscissa and ordinate. It can be concluded that the deflection angle of the controlled wheel and the displacement of the piston rod present has a linear positive correlation, and the linear correlation is stable. This steering control system that uses an electric linear actuator can improve the steering control accuracy on the basis of the differential steering method, and the closed-loop control response is stable and reliable. 


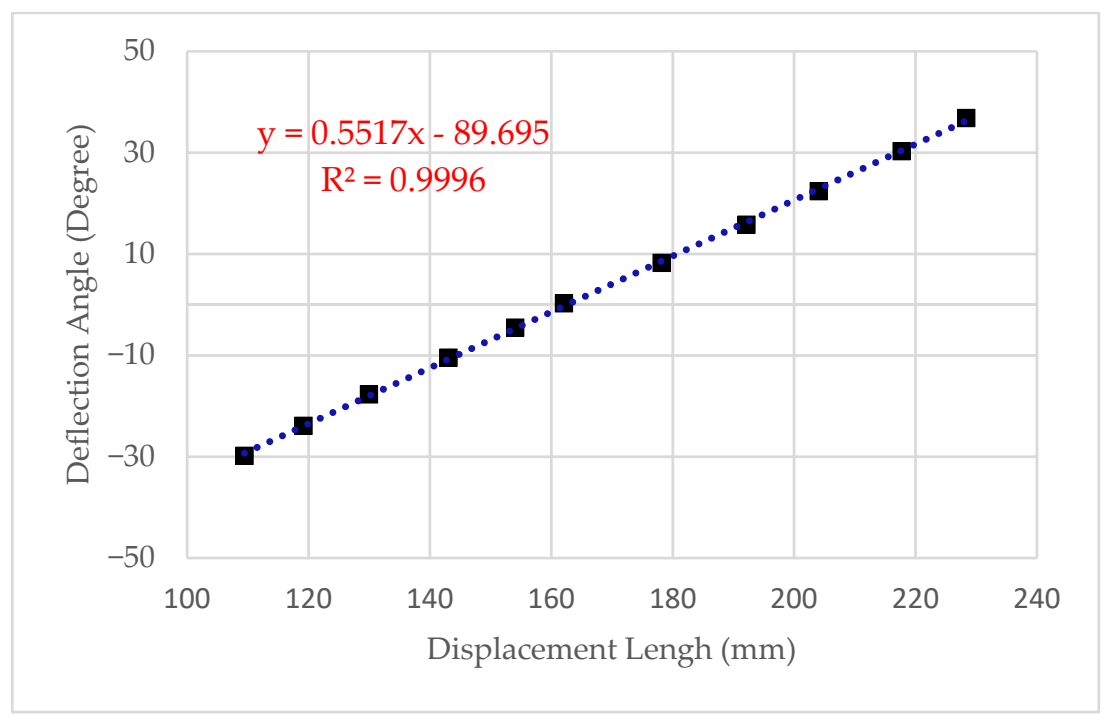

Figure 15. The relationship between the displacement length of the piston rod and the deflection angle of the wheel.

\section{Conclusions}

(1) In this study, for the purpose of relieving the problems of tire sideslip and large turning radius of wheeled agricultural vehicles under complex farmland working environment, a four-wheel independent omnidirectional steering control system was proposed. Compared to the traditional two-wheel differential steering control, which used the speed difference between wheels to change the yaw angular. This kind of steering mechanism has advantages such as being able to accurately control the starting and stopping position during wheel deflection. With higher steering control accuracy, a more reliable control system and a smaller turning radius, it would result in good passing and steering performance under field working conditions.

(2) The fuzzy PID control method was used to realize wheel deflection control, and a controller was established by Matlab / Simulink to simulate and analyze the control of lateral deviation in the process of wheel deflection. The kinematic characteristics of wheel steering mechanism were analyzed by ADAMS, and the thrust change of linear actuator was defined. According to the linear path tracking test under the condition of flat road, the results indicated that the proposed steering mechanism has good stability and control performance. Furthermore, the high steering control accuracy and rapid response of the closed-loop control system ensure that the agricultural vehicle has a good control level in the state of linear tracking.

Author Contributions: Conceptualization, Q.X.; methodology, Q.X.; software, Q.X. and C.W.; validation, Q.X. and C.W.; formal analysis, Q.W.; investigation, Q.W.; resources, Q.X.; data curation, Q.X. and C.W.; writing-original draft preparation, Q.X.; writing-review and editing, Q.X. and H.L.; visualization, Q.X.; supervision, C.W. and Q.W.; funding acquisition, H.L. All authors have read and agreed to the published version of the manuscript.

Funding: This research was funded by the "China Agriculture Research System of MOF and MARA, grant number No. CARS-03" and "Chinese Universities Scientific Fund, grant number No. 2021TC011".

Institutional Review Board Statement: Not applicable.

Informed Consent Statement: Not applicable.

Data Availability Statement: The data used in this study were self-tested and self-collected during the test. As the control method in this paper is still being further optimized, the data cannot be shared at present. Therefore, data sharing is not applicable to this article. 
Acknowledgments: This study was funded by the 2115 Talent Development Program of China Agricultural University.

Conflicts of Interest: The authors declare no conflict of interest.

\section{References}

1. Moysiadis, V.; Tsolakis, N.; Katikaridis, D.; Sørensen, C.G.; Pearson, S.; Bochtis, D. Mobile Robotics in Agricultural Operations: A Narrative Review on Planning Aspects. Appl. Sci. 2020, 10, 3453. [CrossRef]

2. Shamshiri, R.R.; Weltzien, C.; Hameed, I.A.; Yule, I.J.; Chowdhary, G. Research and development in agricultural robotics: A perspective of digital farming. Int. J. Agric. Biol. Eng. 2018, 11, 1-11. [CrossRef]

3. Oliveira, L.F.P.; Moreira, A.P.; Silva, M.F. Advances in Agriculture Robotics: A State-of-the-Art Review and Challenges Ahead. Robotics 2021, 10, 52. [CrossRef]

4. Hang, P.; Chen, X.; Luo, F.; Fang, S. Robust Control of a Four-Wheel-Independent-Steering Electric Vehicle for Path Tracking. SAE Int. J. Veh. Dyn. Stab. NVH 2017, 1, 307-316. [CrossRef]

5. Qiu, Q.; Fan, Z.; Meng, Z.; Zhang, Q.; Cong, Y.; Li, B.; Wang, N.; Zhao, C. Extended Ackerman Steering Principle for the coordinated movement control of a four wheel drive agricultural mobile robot. Comput. Electron. Agric. 2018, 152, 40-50. [CrossRef]

6. Liu, C.; Sun, W.; Zhang, J. Adaptive sliding mode control for 4-wheel SBW system with Ackerman geometry. ISA Trans. 2020, 96, 103-115. [CrossRef]

7. Jiang, Z.; Xiao, B.; Xiao, Y.; Li, H.; Zhang, J. Research on Steering Control Strategy for Steering-by-Wire Four-Wheel Electric Vehicle. In Proceedings of the 2018 2nd IEEE Advanced Information Management, Communicates, Electronic and Automation Control Conference (IMCEC), Xi'an, China, 25-27 May 2018; pp. 80-84.

8. Oksanen, T.; Linkolehto, R. Control of four wheel steering using independent actuators. IFAC Proc. Vol. 2013, 46, 159-163. [CrossRef]

9. Song, L.; Ju, H.; Li, W.; Sun, C.; Yuan, B. Design and Research of Omni-directional Moving AGV. J. Phys. Conf. Ser. 2020, 1575, 012095. [CrossRef]

10. Qu, J.; Guo, K.; Zhang, Z.; Song, S.; Li, Y. Coupling Control Strategy and Experiments for Motion Mode Switching of a Novel Electric Chassis. Appl. Sci. 2020, 10, 701. [CrossRef]

11. Faïza, K.; Rodolfo, O.; Michel, B. Coordinated AFS and DYC for autonomous vehicle steerability and stability enhancement. IFAC Pap. 2020, 53, 14248-14253.

12. Yue, S.; Fan, Y. Hierarchical Direct Yaw-Moment Control System Design for In-Wheel Motor Driven Electric Vehicle. Int. J. Automot. Technol. 2018, 19, 695-703. [CrossRef]

13. Ding, S.; Liu, L.; Zheng, W.X. Sliding Mode Direct Yaw-Moment Control Design for In-Wheel Electric Vehicles. IEEE Trans. Ind. Electron. 2017, 64, 6752-6762. [CrossRef]

14. Peng, H.; Wang, W.; An, Q.; Xiang, C.; Li, L. Path Tracking and Direct Yaw Moment Coordinated Control Based on Robust MPC With the Finite Time Horizon for Autonomous Independent-Drive Vehicles. IEEE Trans. Veh. Technol. 2020, 69, 6053-6066. [CrossRef]

15. Yong, J.; Gao, F.; Ding, N.; He, Y. An integrated algorithm for vehicle stability improvement with the coordination of direct yaw moment and four-wheel steering control. Int. J. Veh. Des. 2017, 74, 231-256. [CrossRef]

16. Chen, L.; Li, Z.; Yang, J.; Song, Y. Lateral Stability Control of Four-Wheel-Drive Electric Vehicle Based on Coordinated Control of Torque Distribution and ESP Differential Braking. Actuators 2021, 10, 135. [CrossRef]

17. Kasinathan, D.; Kasaiezadeh, A.; Wong, A.; Khajepour, A.; Chen, S.K.; Litkouhi, B. An Optimal Torque Vectoring Control for Vehicle Applications via Real-Time Constraints. IEEE Trans. Veh. Technol. 2016, 65, 4368-4378. [CrossRef]

18. Wang, J.; Wang, Q.; Jin, L.; Song, C. Independent wheel torque control of 4WD electric vehicle for differential drive assisted steering. Mechatronics 2010, 21, 63-76. [CrossRef]

19. Yin, D.; Wang, J.; Du, J.; Chen, G.; Hu, J. A New Torque Distribution Control for Four-Wheel Independent-Drive Electric Vehicles. Actuators 2021, 10, 122. [CrossRef]

20. Chen, L.; Li, P.; Lin, W.; Zhou, Q. Observer-Based Fuzzy Control for Four-Wheel Independently Driven Electric Vehicles with Active Steering Systems. Int. J. Fuzzy Syst. 2020, 22, 89-100. [CrossRef]

21. Sun, H.; Li, H.; Li, Y.; Song, Z.; Xu, K. Accelerating the Validation of Motion Control for a 4WD4WS Ground Vehicle Using a Hierarchical Controller Hardware-in-the-loop System*. In Proceedings of the 2019 IEEE International Conference on Robotics and Biomimetics (ROBIO), Dali, China, 6-8 December 2019; pp. 2396-2401.

22. Yutian, Z.; Jun, N.; Hanqing, T.; Wei, W.; Jibin, H. Integrated robust dynamics control of all-wheel-independently-actuated unmanned ground vehicle in diagonal steering. Mech. Syst. Signal. Process. 2022, 164, 108263.

23. Ren, B.; Chen, H.; Zhao, H.; Yuan, L. MPC-based yaw stability control in in-wheel-motored EV via active front steering and motor torque distribution. Mechatronics 2016, 38, 103-114. [CrossRef]

24. Tu, X.; Gai, J.; Tang, L. Robust navigation control of a 4WD/4WS agricultural robotic vehicle. Comput. Electron. Agric. 2019, 164, 104892. [CrossRef]

25. Zhang, M.; Ji, Y.; Li, S.; Cao, R.; Xu, H.; Zhang, Z. Research Progress of Agricultural Machinery Navigation Technology. Trans. Chin. Soc. Agric. Mach. 2020, 51, 1-18. 
26. Sharma, R.; Deepak, K.K.; Gaur, P.; Joshi, D. An optimal interval type-2 fuzzy logic control based closed-loop drug administration to regulate the mean arterial blood pressure. Comput. Methods Programs Biomed. 2020, 185, 105167. [CrossRef] [PubMed]

27. Xu, Q.; Li, H.; He, J.; Wang, Q.; Lu, C.; Wang, C. Design and experiment of the self-propelled agricultural mobile platform for wheat seeding. Trans. Chin. Soc. Agric. Eng. 2021, 37, 1-11.

28. Lin, H.; Dong, S.; Liu, Z.; Yi, C. Study and Experiment on a Wheat Precision Seeding Robot. J. Robot. 2015, $2015,12$.

29. Chatzikomis, C.I.; Spentzas, K.N. Comparison of a vehicle equipped with Electronic Stability Control (ESC) to a vehicle with Four Wheel Steering (4WS). Forsch. Ing. 2014, 78, 13-25. [CrossRef]

30. Tabbache, B.; Kheloui, A.; Benbouzid, M.E.H. An Adaptive Electric Differential for Electric Vehicles Motion Stabilization. IEEE Trans. Veh. Technol. 2011, 60, 104-110. [CrossRef]

31. Zhang, J.; Chen, D.; Wang, S.; Hu, X.; Wang, D. Design and experiment of four-wheel independent steering driving and control system for agricultural wheeled robot. Trans. Chin. Soc. Agric. Eng. 2015, 31, 63-70.

32. Guo, X.; Chen, Y.; Li, H. Research on Steering Stability Control of Electric Vehicle Driven by Dual In-Wheel Motor. In Proceedings of the 2020 10th Institute of Electrical and Electronics Engineers International Conference on Cyber Technology in Automation, Control, and Intelligent Systems (CYBER), Xi'an, China, 10-13 October 2020.

33. Chen, G.; Li, Z.; Zhang, Z.; Li, S. An Improved ACO Algorithm Optimized Fuzzy PID Controller for Load Frequency Control in Multi Area Interconnected Power Systems. IEEE Access 2020, 8, 6429-6447. [CrossRef]

34. Ma, S.; He, Y.; Li, G.; Li, M.; Li, H. Design and Optimization of the Steering Mechanism of Four-wheel Steering Elevated Vehicle. J. Agric. Mech. Res. 2018, 40, 252-256.

35. Bouakkaz, M.S.; Boukadoum, A.; Boudebbouz, O.; Fergani, N.; Boutasseta, N.; Attoui, I.; Bouraiou, A.; Necaibia, A. Dynamic performance evaluation and improvement of PV energy generation systems using Moth Flame Optimization with combined fractional order PID and sliding mode controller. Sol. Energy 2020, 199, 411-424. [CrossRef] 